Gut, 1971, 12, 268-275

\title{
Treatment of achalasia with pneumatic dilatations
}

\author{
G. VANTRAPPEN, J. HELlEMANS, W. DELOOF, P. VALEMBOIS, AND \\ J. VANDENBROUCKE
} From the Department of Medicine and the Laboratory of Gastrointestinal Physiopathology,
Akademisch Ziekenhuis, St Rafaël, Leuven, Belgium

SUMMARY During the last 13 years 264 unselected patients with achalasia have been treated solely by the technique of pneumatic dilatation. The principle of the method was to continue the series of consecutive dilatations until the result was satisfactory. This paper reports the late results in 138 patients who were treated more than three years ago (3-13 years; mean 6.6 years). The results were evaluated by somebody who had not before been involved in the treatment of achalasia. The evaluation was based on a personal interview, a standardized radiological examination, and intraluminal pressure measurements.

These late results were classified as excellent in $45 \%$, good in $32 \%$, moderate in $17 \%$, and poor in $6 \%$. The best results were obtained in patients with a history of five to twenty years and a moderately dilated oesophagus $(50-80 \mathrm{~mm}$.). Comparison of the clinical results with the manometric data obtained before, immediately after, and late after treatment indicates that intraluminal pressure measurements may be a useful guide for the treatment of achalasia by pneumatic dilatations.

The treatment of achalasia is still a matter of controversy. Forceful dilatation by pneumatic, hydrostatic, or mechanical means is advocated by some authors (Olsen, Harrington, Moersch, and Andersen, 1959; Van Goidsenhoven, Vantrappen, Verbeke, and Vandenbroucke, 1963; Affolter and Voegeli, 1969), whereas others prefer Heller's procedure or one of its modifications (Malm, 1956; Ferguson and Burford, 1960; Ellis, Kiser, Schlegel, Earlam, McVey, and Olsen, 1967). In order to evaluate objectively the technique of forceful dilatation we planned to treat a large and unselected group of patients with one technique applicable to all patients with achalasia. To reduce the brusqueness and blindness of the method we decided to use a series of consecutive dilatations with progressively larger balloons and to continue the dilatations until the supradiaphragmatichigh pressure zone was abolished on intraluminal pressure measurements. Previous studies have indicated that the absence of the supradiaphragmatic portion of the high pressure zone is a characteristic feature of a successful Heller's procedure (Olsen, Schlegel, Creamer, and Ellis, 1957).

\section{Materials and Methods}

PATIENTS

All but six of the 264 patients with achalasia referred Received for publication 18 December 1970. to our unit during the last 13 years have been treated by the single technique of pneumatic dilatation. The major contraindications, requiring a different type of treatment, included lack of cooperation in two psychotic patients and one child aged 8, and the presence of a concomitant lesion necessitating surgical intervention (carcinoma of the gastric fundus in one patient, suspected carcinoma in another, and a destroyed lung in a third patient). One hundred and thirty-eight patients had been dilated more than three years before the last follow-up study. Twenty-nine patients had previously been treated unsuccessfully with mercury bougie dilatations. Eight other patients were failures of one or more Heller operations. There were 66 men and 69 women. The ages at the time of treatment varied from 12 to 82 years (mean 46.5) (Fig. 1). There were 10 septuagenarians and three octogenarians; advanced age was not taken as a contraindication for pneumatic dilatation. The duration of symptoms up to the time of treatment ranged from one month to 60 years. The mean duration of symptoms was $7 \cdot 6$ years (Fig. 2).

The subjective complaints of the patients at the time of treatment with pneumatic dilatation are summarized in Figure 3. Dysphagia for liquids and solids was the most prominent symptom and was present in all but one patient. Sixty-nine percent 


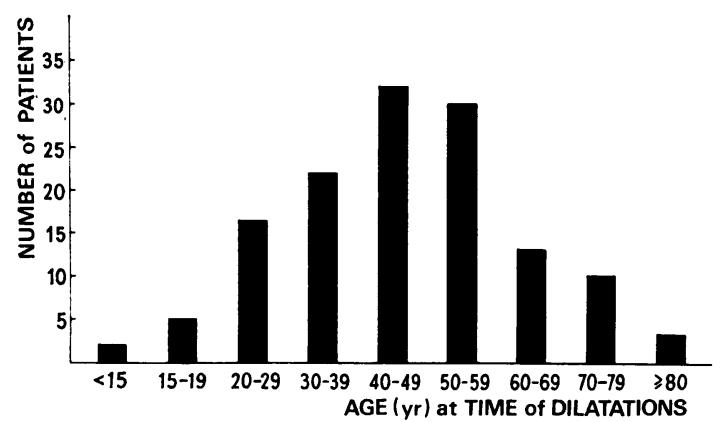

Fig. 1. Age of the patients at time of pneumatic dilatations.

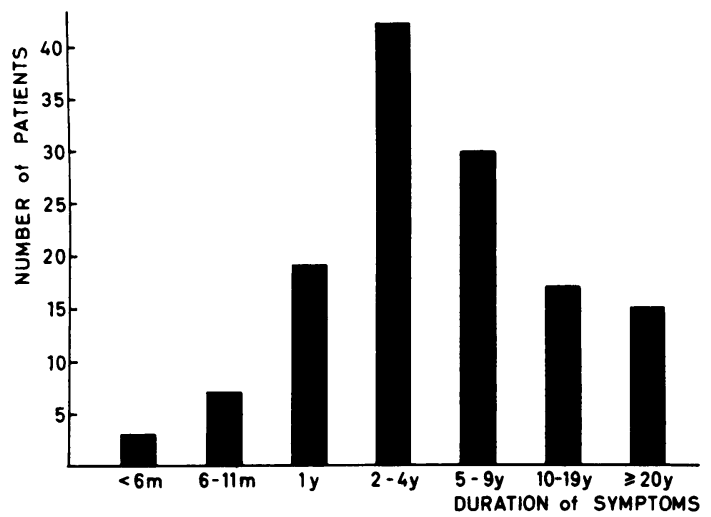

Fig. 2. Duration of symptoms before treatment with pneumatic dilatations.

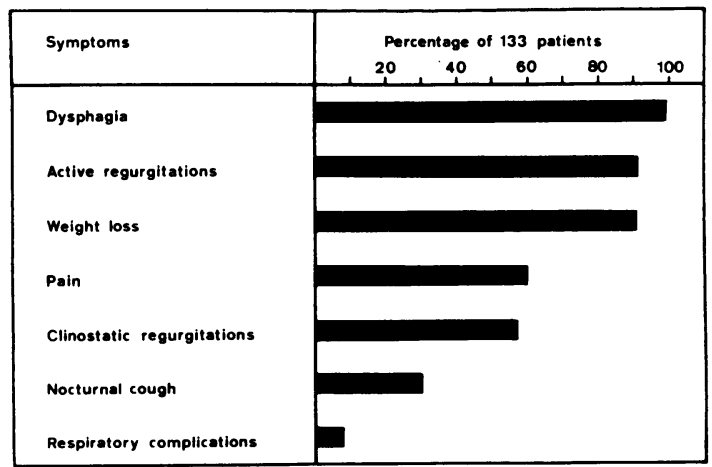

Fig. 3. Incidence of various symptoms in 133 patients with achalasia immediately before treatment with pneumatic dilatations. of the patients had more trouble with solids than with fluids, $22 \%$ had not noted any difference between solids or fluids, and only $7 \%$ experienced more trouble with liquids than with solids. Most patients (91\%) had dysphagia at each meal, $7 \%$ daily, and $2 \%$ three to four times a week. Precordial pain was experienced by $60 \%$ of the patients. Attacks of cramp-like retrosternal pain, not related to meals and frequently radiating to the neck or the back, were present in $46 \%$ of the patients. Active prandial or postprandial regurgitation occurred in $91 \%$, whereas regurgitation in the recumbent position were present in only $57 \%$ of the patients. Stagnation of large amounts of food and secretion in the dilated oesophagus resulted in nocturnal coughing in $30 \%$ and in bronchopulmonary complications in $7.5 \%$ of the patients. Weight loss was present in $91 \%$; 16 patients had lost more than $20 \mathrm{~kg}, 18$ less than $5 \mathrm{~kg}$ in weight.

Fluoroscopic and radiographic examinations of the oesophagus and stomach were performed in all patients. At the time of the follow-up study the original radiological records of 128 patients were available. The maximal diameter varied from $34 \mathrm{~mm}$ to $95 \mathrm{~mm}$, with a mean of $55 \mathrm{~mm}$. The oesophagus was slightly dilated $(<50 \mathrm{~mm})$ in $38 \%$ of these patients, moderately dilated $(50-79 \mathrm{~mm})$ in $55 \%$, and enormously dilated (>80 mm) in $7 \%$ (Table 1 ). The incidence of food residue in the fasting oesophagus, of elongation and tortuosity of the gullet, and of disappearance of the air bubble in the gastric fundus all increased significantly with an increasing oesophageal diameter $(\mathrm{P}<0.01)$. The degree of dilatation of the gullet correlates well with the duration of symptoms $(P<0.001)$ (Table II). A sigmoid appearance of the oesophagus was not taken as a contraindication for pneumatic dilatations; it was observed in $29 \%$ of the patients. The mean maximal diameter of the lower oesophageal sphincter segment before treatment was $2 \mathrm{~mm}$.

The manometric studies were performed with the use of three to six water-filled, non-perfused opentip catheters. The technique of intraluminal pressure measurements and the manometric observations in patients with achalasia have already been described (Vantrappen, Van Goidsenhoven, Van den Berghe, Verbeke, and Vandenbroucke, 1963). The resting pressures in the lower oesophageal sphincter were used as a guide for the treatment by pneumatic dilatation; these pressures were within the normal range in all patients before treatment (mean endexpiratory pressure $5.6 \pm 0.68 \mathrm{~mm} \mathrm{Hg}$ at $0.5 \mathrm{~cm}$ above the 'diaphragmatic hiatus').

METHOD OF TREATMENT

The method of treatment has been described pre- 


\begin{tabular}{|c|c|c|c|c|c|c|c|}
\hline \multirow{2}{*}{$\begin{array}{l}\text { Diameter of } \\
\text { Oesophagus } \\
(\mathrm{mm})\end{array}$} & \multirow{2}{*}{$\begin{array}{l}\text { No. of } \\
\text { Patients }\end{array}$} & \multicolumn{2}{|l|}{ Food Remnants } & \multicolumn{2}{|c|}{ Oesophageal Elongation } & \multicolumn{2}{|c|}{ Absence of Gastric Airbubble } \\
\hline & & No. of Patients & Percentage & No. of Patients & Percentage & No. of Patients & Percentage \\
\hline
\end{tabular}

Table I Radiological appearance of oesophagus in 128 patients with achalasia immediately before treatment with pneumatic dilatations

\begin{tabular}{lcc}
\hline $\begin{array}{l}\text { Diameter of } \\
\text { Oesophagus before } \\
\text { Treatment }(\mathrm{mm})\end{array}$ & No. of Patients & $\begin{array}{l}\text { Mean Duration of } \\
\text { Symptoms }(\mathrm{mth})\end{array}$ \\
\hline$<50$ & 49 & $50 \cdot 5$ \\
$50-79$ & 70 & $96 \cdot 2$ \\
$>80$ & 9 & 167.5
\end{tabular}

Table II Relation between maximal diameter of oesophagus and the duration of symptoms before treatment

viously (Vantrappen, Van Goidsenhoven, and Vandenbroucke, 1961; Van Goidsenhoven et al, 1963). Briefly, the dilatations are performed with balloons of progressively larger diameter and the treatment is continued until the result is thought to be satisfactory, as judged by clinical, radiological, and manometric criteria. Before dilatation the patient swallows a string (Mersilene no. 1) weighted by a mercury-filled bag. Once the bag reaches the small bowel it anchors and the string becomes a guide for the passage of the dilator. A metal wire, with an eye at the end, is threaded over the string into the stomach and provides a rigid guide for the safe passage of the dilator. The correct position of the balloon is checked by fluoroscopy. When in place the balloon is insufflated to a pressure of $200 \mathrm{~mm} \mathrm{Hg}$ for the first minute, then to $300 \mathrm{~mm}$ $\mathrm{Hg}$ for an additional minute. Initially a balloon with a diameter of $3 \mathrm{~cm}$ is used, then at subsequent dilatations the diameter of the balloon is increased to $3 \cdot 5,3 \cdot 8,4,4 \cdot 2,4 \cdot 5$, and occasionally $5 \mathrm{~cm}$. The clinical and radiological criteria used to determine the number of dilatations included disappearance of dysphagia, ease in emptying the oesophagus, and broadening of the previously narrow lower oesophageal segment. Manometric criteria were decisive whenever possible. The dilatations were continued until the supradiaphragmatic portion of the high pressure zone was completely or almost completely abolished. Two to four dilatations were usually needed. The mean number of dilatations per patient was $3 \cdot 2$.

\section{FOLLOW-UP STUDIES}

The majority of the patients have been seen at intervals since treatment. All living patients, treated more than three years before the follow-up study, were invited to the hospital for control examinations Follow-up data are available on 133 patients $(96 \%$ of the group). Fifteen patients died before the final analysis. We evaluated the result of treatment in these patients from their most recent hospital records and from data obtained from interviews with the family and/or the family doctor. The remaining 118 patients were examined by one of us (W.D.) who had not hitherto been involved in the treatment of achalasia. This examination included an interview and an extensive questionnaire designed to obtain as precise information as possible on the incidence and degree of dysphagia, substernal distress or pain, bronchopulmonary symptoms, weight change, and heartburn. Other types of subsequent treatment were also noted, and a radiological examination of the oesophagus and gastrooesophageal region was carried out in 116 patients. We measured the maximal diameters of the oesophagus and the lower oesophageal sphincteric segment, and determined the presence and degree of stagnating food or fluids in the fasting oesophagus and of air in the gastric fundus. We noted whether the oesophagus was elongated and tortuous. The ease of emptying was evaluated by measuring the height of the barium column 10 seconds and 20 seconds following the ingestion of a standard barium meal. Gastrooesophageal reflux was measured with the patient in a slightly head-down position on his right side in dorsal decubitus.

Intraluminal pressure measurements were performed in all patients who, after having passed the previous examinations, were sufficiently courageous to swallow the tubes (74 patients). The pressure tracings were analysed by a colleague who was unaware of the result of the clinical and radiological studies.

The duration of the follow-up period ranges from less than three years in five patients who died within three years of treatment to 12 years (Table III). The mean duration of follow up was $6 \cdot 6$ years.

\section{Results}

IMMEDIATE RESULTS AND COMPLICATIONS OF TREATMENT

By the end of the treatment all patients stated that 
they were able to eat without distress. Regurgitation had also disappeared completely. The attacks of retrosternal pain did not always disappear immediately; in some cases it was several weeks before relief was obtained. Most patients regained weight, often with surprising rapidity.

\begin{tabular}{ll}
\hline Duration of Follow Up $(y r)$ & No. of Patients \\
\hline$<3$ & 5 \\
$3-4$ & 32 \\
$5-6$ & 45 \\
$7-8$ & 24 \\
$9-10$ & 15 \\
$11-12$ & 12 \\
\hline
\end{tabular}

Table III Duration of follow-up period after treatment

The mortality rate of the treatment was zero in this series as well as in the patients treated more recently, 264 cases in all. The oesophagus was perforated in three patients. An empyema was drained surgically in one patient; the other two were treated with antibiotics and parenteral feeding. All three recovered completely and are now free of symptoms. An aseptic pleural effusion occurred in three patients and a pericardial effusion in one. Medical treatment for a few days always resulted in prompt recovery. Haemorrhage was observed in two patients, requiring a blood transfusion of $500 \mathrm{ml}$ in one of them. A febrile reaction without any other demonstrable lesion was observed in four patients. Although complications occurred in $11.3 \%$ of this group, complications were serious in only two patients, requiring surgical drainage in one and blood transfusion in another.

\section{LATE RESULTS}

The clinical evaluation of these 138 patients was based upon the incidence and degree of dysphagia, retrosternal pain, regurgitation, and weight loss. These criteria were used to divide the patients into four groups. Group 1 (excellent results) included those patients who are now completely free of symptoms. Group 2 (good results) are those patients who occasionally experience dysphagia or pain of short duration, ie, less than once a week when food sticks retrosternally; this lasts from a few seconds to a couple of minutes and disappears on drinking some fluid. There is no weight loss and no regurgitation. Group 3 (moderate results) patients experience dysphagia at least once a week. The sensation of food sticking in the oesophagus does not last longer than a few minutes and does not prevent the patient from continuing and finishing his meal. It is not accompanied by regurgitation or weight loss. There is a marked improvement compared with their pre- treatment state. Group 4 (poor results) patients regularly have dysphagia lasting for minutes, or dysphagia accompanied by regurgitation, or daily retrosternal pain.

At the time of clinical evaluation, three to 13 years after treatment, the result of the pneumatic dilatations was excellent or good (group 1 or 2) in $77 \%$ of the 133 patients and moderate or poor (group 3 or 4 ) in $23 \%$ (Table IV). If the same classi-

\begin{tabular}{|c|c|c|c|c|}
\hline \multirow{2}{*}{$\begin{array}{l}\text { Clinical } \\
\text { Evaluation }\end{array}$} & \multicolumn{2}{|c|}{ Before Treatment } & \multicolumn{2}{|c|}{ Late after Treatment } \\
\hline & $\begin{array}{l}\text { No. of } \\
\text { Patients }\end{array}$ & Percentage & $\begin{array}{l}\text { No. of } \\
\text { Patients }\end{array}$ & Percentage \\
\hline $\begin{array}{l}\text { Group } 1 \\
\text { (excellent) }\end{array}$ & - & 一 & $60(2)^{1}$ & $45 \cdot 1$ \\
\hline $\begin{array}{l}\text { Group } 2 \\
\text { (good) }\end{array}$ & 一 & - & $42(5)$ & $31 \cdot 6$ \\
\hline $\begin{array}{l}\text { Group } 3 \\
\text { (moderate) }\end{array}$ & 14 & $10 \cdot 5$ & $23(6)$ & $17 \cdot 3$ \\
\hline $\begin{array}{l}\text { Group } 4 \\
\text { (poor) }\end{array}$ & 119 & $89 \cdot 5$ & $8(3)$ & 6 \\
\hline
\end{tabular}

Table IV Late results obtained in 133 patients

${ }^{1}$ Figures in parentheses give the number of patients who have had two or three series of dilatation.

fication is applied to the state before treatment, $90 \%$ of the patients belong to group 4 and $10 \%$ to group 3. Heartburn was noted occasionally in 31 patients; it occurred at a frequency of about once a week in five patients but no patient had daily complaints of heartburn. Associated diseases at the time of clinical evaluation included five duodenal ulcers, one gastric and one bronchial carcinoma, and three patients with rheumatoid arthritis. Oesophageal carcinoma was observed in one patient. Fifteen patients had died at the time of the follow-up study. In none of these patients was the cause of death related to the achalasia.

The radiological examinations indicate that the dilatations resulted in an immediate and sustained reduction in the diameter of the oesophagus. Even the nine grossly enlarged oesophagi ( $>80 \mathrm{~mm}$ diameter) decreased from a mean diameter of $92 \mathrm{~mm}$ to a mean value of $68.1 \mathrm{~mm}(\mathrm{P}<0.05)$. A return to normal was observed only if the oesophageal diameter before treatment was not larger than 70 $\mathrm{mm}$ (Table V). The mean maximum diameter of the lower oesophageal sphincter increased from $2 \mathrm{~mm}$ before treatment to $9 \mathrm{~mm}$ late after treatment $(P<0.005)$. The elongation and tortuosity of the oesophagus were hardly affected. A return to normal length was observed in only four of the 30 elongated oesophagi. Solid food remnants after an overnight fast were observed in 53 oesophagi before, and in 14 oesophagi late after pneumatic dilatations. Before treatment the gastric air bubble was absent in 102 


\begin{tabular}{|c|c|c|c|c|c|c|}
\hline \multirow{2}{*}{$\begin{array}{l}\text { Diameter of } \\
\text { Oesophagus (mm) }\end{array}$} & \multicolumn{2}{|c|}{ Before Treatment } & \multicolumn{2}{|c|}{ Immediately after Treatment } & \multicolumn{2}{|c|}{ Late after Treatment } \\
\hline & No. of Patients & Mean & Mean & Range & Mean & Range \\
\hline $\begin{array}{r}<40 \\
40-49 \\
50-59 \\
60-69 \\
70-79 \\
80-89 \\
90-99 \\
\geqslant 100\end{array}$ & $\begin{array}{r}18 \\
30 \\
23 \\
20 \\
16 \\
3 \\
3 \\
3\end{array}$ & $\begin{array}{r}35.0 \\
44.0 \\
53.2 \\
63.0 \\
72.0 \\
81.0 \\
91.7 \\
103.3\end{array}$ & $\begin{array}{l}27 \cdot 6 \\
34 \cdot 3 \\
35 \cdot 4 \\
45 \cdot 0 \\
41 \cdot 7 \\
53 \cdot 3 \\
76 \cdot 7 \\
73 \cdot 7\end{array}$ & $\begin{array}{l}16-38 \\
20-48 \\
26-50 \\
27-71 \\
33-60 \\
43-70 \\
70-90 \\
55-90\end{array}$ & $\begin{array}{l}28 \cdot 1 \\
33 \cdot 6 \\
33 \cdot 3 \\
49 \cdot 3 \\
51 \cdot 0 \\
67 \cdot 0 \\
66 \cdot 3 \\
72 \cdot 0\end{array}$ & $\begin{array}{l}18-42 \\
23-60 \\
19-45 \\
30-78 \\
32-89 \\
50-80 \\
62-70 \\
41-100\end{array}$ \\
\hline
\end{tabular}

Table V Diameter of oesophagus in 116 patients with achalasia before, immediately after, and late after treatment

of the 118 patients; late after treatment it was found to be present in all but 10 patients. The ease of emptying was estimated by measuring the height of the barium column 10 and 20 seconds after drinking $200 \mathrm{ml}$ of contrast medium. The mean height of the column in the patients in groups 1 and 2 was $65 \mathrm{~mm}$ after 10 seconds and $50 \mathrm{~mm}$ after 20 seconds, and in the patients in groups 3 and $480 \mathrm{~mm}$ and $70 \mathrm{~mm}$ respectively. Gastrooesophageal reflux was looked for but not observed.

\section{FACTORS INFLUENCING THE RESULT OF TREATMENT}

Several factors were studied which could possibly have influenced the result of treatment (Table VI). If the duration of the follow-up period was less than five years the percentage of satisfactory results (excellent or good) was higher than with longer periods of follow-up. It may be noted, however; that after this initial decline the result seemed to become stabilized. If the duration of symptoms before treatment was less than five years, pneumatic dilatations were significantly less effective than with longer periods of symptoms $(68 \%$ of good results versus $87 \%$; $P<0.025$ ). Moreover patients who had developed a recurrence had a mean duration of symptoms before treatment of 2.5 years, whereas the duration of symptoms in patients who did not develop a recurrence averaged 8.2 years. The age of the patients at the onset of symptoms also influenced the results obtained: patients over the age of $\mathbf{4 5}$ did better than the younger ones (87.5\% and $70 \%$ of good results respectively; $P<0.025$ ). A similar tendency was observed for the age at the time of treatment $(84.2 \%$ and $66.6 \%$ of satisfactory results respectively; $\mathbf{P}<0.05$ ). Moreover, the mean age at the time of pneumatic dilatations in those patients who had developed a recurrence was 30 years, whereas the age of those who had not was 49 years. If the result of treatment is correlated with the diameter of the oesophagus before dilatations it seems that the best results are obtained in patients with a moderately dilated gullet.

\begin{tabular}{lll}
\hline & \multicolumn{2}{c}{ Incidence of Excellent or Good Results } \\
\cline { 2 - 3 } & No. of Patients & Percentage \\
\hline $\begin{array}{l}\text { Duration of follow up } \\
\text { (yr) }\end{array}$ & \\
$<5$ & 32 & \\
$5-10$ & 54 & $86 \cdot 5$ \\
$>10$ & 16 & 73 \\
& & $72 \cdot 7$ \\
Duration of symptoms & & \\
(yr) & & \\
$<5$ & 48 & $67 \cdot 6$ \\
$5-20$ & 42 & 89 \\
$>20$ & 12 & 80 \\
& & \\
Age at onset (yr) & 22 & $62 \cdot 8$ \\
$<30$ & 38 & 76 \\
$30-44$ & 32 & $88 \cdot 8$ \\
$45-60$ & 10 & $83 \cdot 3$ \\
$>60$ & & \\
& & $60 \cdot 8$ \\
Age at treatment $(y r)$ & 14 & $70 \cdot 6$ \\
$<30$ & 24 & $81 \cdot 6$ \\
$30-44$ & 40 & $88 \cdot 8$ \\
$45-60$ & 24 & \\
$>60$ & & $71 \cdot 4$ \\
Diameter of oesophagus & $86 \cdot 6$ \\
(mm) & 35 & \\
$<50$ & 57 & \\
$50-80$ & 6 & \\
$>80$ & &
\end{tabular}

Table VI Factors possibly influencing the result of the treatment by pneumatic dilatation

NUMBER OF DILATATIONS INFLUENCING

THE RESULT OF TREATMENT

Although the technique of pneumatic dilatation was similar in all patients, the number of dilatations and the maximal diameter of the dilating balloon were individually determined according to clinical, radiological, and especially manometric criteria. There was no relation between the number of dilatations and the results obtained. The mean number of dilatations was 3.16 for patients of groups 1 and 2, 3.19 for patients of groups 3 and 4 , and 3.26 for those who developed a recurrence.

The maximal diameter of the dilating balloon was not significantly different in patients with satisfactory and in those with an unsatisfactory result 
$(38.6 \mathrm{~mm}$ and $37.2 \mathrm{~mm}$; $P>0.05)$. Similarly, the maximal diameter of the dilator used was not significantly different in patients who did and in those who did not develop a recurrence $(37.3 \mathrm{~mm}$ and $38.4 \mathrm{~mm}$ respectively; $\mathrm{P}>0.05$ ).

As this study was planned it was decided that the series of pneumatic dilatations should be continued until complete or almost complete disappearance of the supradiaphragmatic high pressure zone. For several reasons (non-cooperation of the patient, complications or fear of complications) it was not always possible to achieve this aim. This enabled us to correlate the present clinical status of the patients with the manometric observations before, immediately after, and late after treatment. The pressure profiles in Figs. 4 and 5 illustrate the relation between the late results of treatment and the resting pressures in the lower oesophageal sphincter. The result is called satisfactory if the patients belong to group 1 or 2 , unsatisfactory if they belong to groups 3 or 4 or if they had a recurrence. Before treatment both the patients with satisfactory and with unsatisfactory results had identical pressure profiles. At the completion of treatment patients with unsatisfactory results had significantly higher resting pressures than the 'satisfactory' patients, in whom the high pressure zone was almost completely abolished $(\mathrm{P}<0.01$ for the levels $0.5 \mathrm{~cm}$ below, $0.5 \mathrm{~cm}$ above, and $1.5 \mathrm{~cm}$ above the pressure inversion point or 'diaphragmatic hiatus'). This difference between both categories was still present at the time of the follow-up studies. At that time, however, patients with unsatisfactory results were found to have higher resting pressures not only in the lower sphincter but also in the oesophagus proper $(P<0.05$ for all levels from $0.5 \mathrm{~cm}$ below to $6-8 \mathrm{~cm}$ above the 'diaphragmatic hiatus'). The resting pressure in the oesophagus of these patients returned to the high levels measured before treatment. In the patients with satisfactory results the

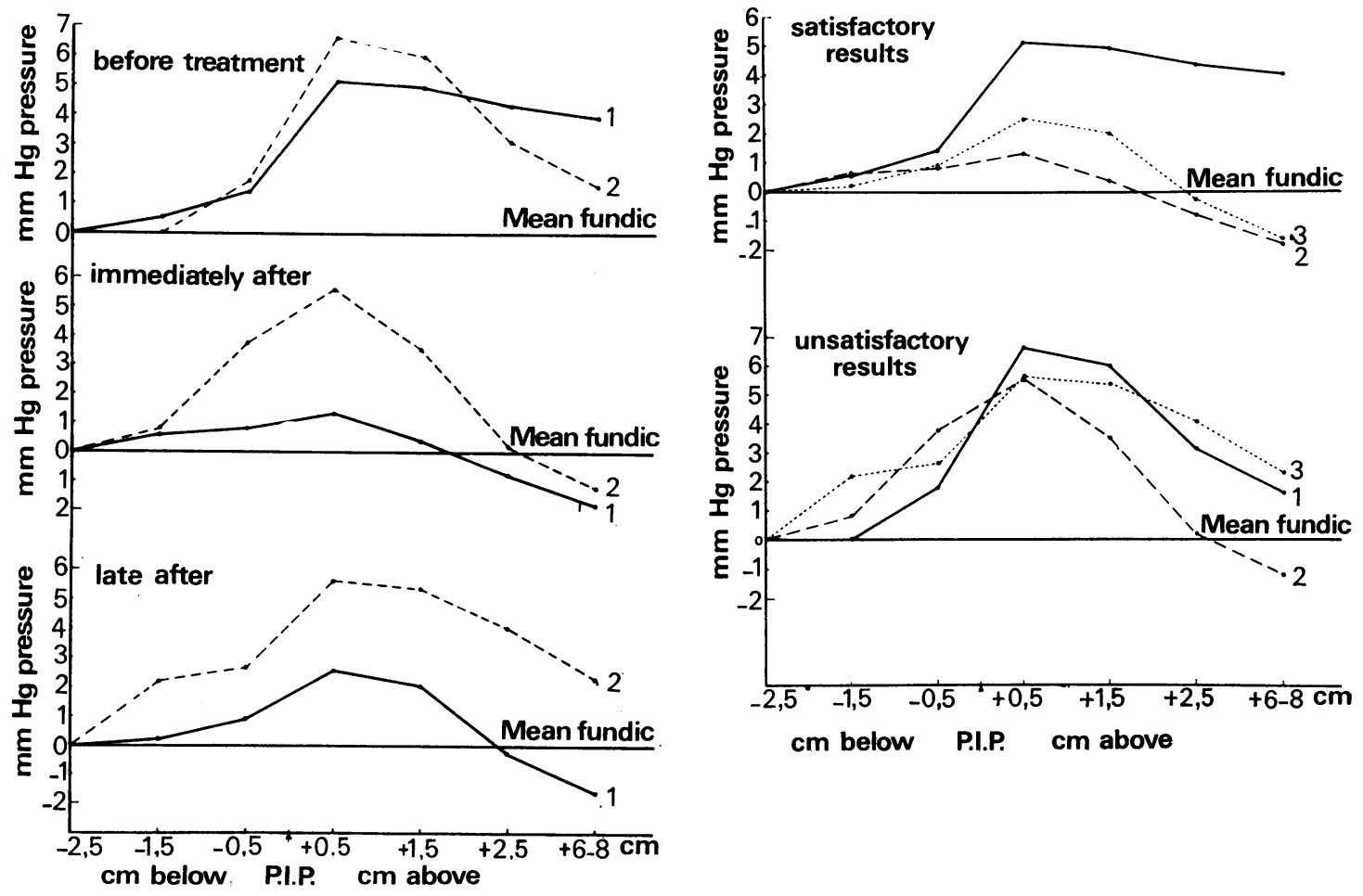

Fig. 4. Mean end-expiratory resting pressures in lower oesophageal sphincter of patients with achalasia, before (upper diagram), immediately after (middle diagram), and late after treatment (lower diagram). Continuous line indicates patients with satisfactory results (groups 1 and 2); and broken line patients with unsatisfactory results (groups 3 and 4, and recurrences).

Fig. 5. Mean end-expiratory resting pressures in lower oesophageal sphincter of patients with achalasia, treated with satisfactory results (upper diagram) and with unsatisfactory results (lower diagram). Line 1 before treatment; line 2 immediately after treatment; line 3 late after treatment. 
resting sphincteric pressures tended to be somewhat higher at the time of the follow-up study as compared to the pressures immediately after the dilatations, but they remained significantly lower than the pressures before treatment $(P<0.01)$.

\section{Discussion}

Treatment of achalasia is at present necessarily directed towards the relief of the functional obstruction at the cardia. Forceful dilatations and the Heller operation are the two methods most frequently used for this purpose. The technique of pneumatic dilatations, used in this study, aims at reducing the brusqueness and blindness which characterize most methods of forceful dilatation of the cardia. Instead of using an instrument with a fixed diameter, the diameter of the dilating balloon was progressively increased during consecutive dilatations in order to meet the individual needs of each patient. The blindness was further decreased by the clinical and radiological controls but especially by the pressure measurements, carried out before the dilatations were started, with another and larger balloon. Based upon the observation that a successful treatment of achalasia is characterized manometrically by the disappearance of the supradiaphragmatic high pressure zone (Olsen et al, 1957; Vantrappen, 1961), it was planned to continue the series of dilatations until this effect was achieved, unless serious clinical considerations indicated a sudden interruption.

The best method for the comparative evaluation of the technique of forceful dilatations and the Heller operation would probably be to treat at random a series of patients with one technique or the other. For various reasons this method could not be used in our hospital. To make possible an objective evaluation of the technique of forceful dilatations the following criteria for the management and the follow-up analysis of the patients were set out from the onset of the study. One single technique would be used in all patients; a sufficiently large number of unselected patients would be treated; the follow-up period would be sufficiently long and the follow-up studies would include a personal interview with the patients with the aid of a detailed questionnaire, and radiological and manometric controls. All but six of the 264 patients referred to our unit during the last 13 years have been treated by one single technique of pneumatic dilatations. The main contraindication for treatment by this technique was the impossibility of the patient to cooperate because of psychosis or youth. The technique of guided introduction of the instrument made it possible to dilate all cases of achalasia, irrespective of the size and shape of the oesophagus. To illustrate the fact that this is an essentially unselected group of patients it may be pointed out that the following conditions were not taken as a contraindication for pneumatic dilatations: recurrence following a previous Heller's procedure (eight patients); previous unsuccessful dilatation with mercury bougies (21 patients); advanced age of the patients (three octogenarians, 10 septuagenarians); a tortuous and sigmoid-shaped oesophagus (38 patients); coronary insufficiency (one patient had a pace-maker implanted): and a sliding hiatal hernia.

The follow-up period is relatively long (three to 13 years, mean 6.6 years) and follow-up data are available for 133 of the 138 patients treated. To eliminate as much as possible any bias in the evaluation of the late results the follow-up studies were performed by a colleague who had not before been involved in the treatment of achalasia. The personal interview with the patients, the standardized $x$-ray examination, and the classification of the patients into groups according to the result obtained were all done by one of us (W.D.).

A careful history is probably the most important single tool for the evaluation of the result of the treatment of oesophageal disorders. It is obviously not sufficient to know what percentage of the patients has experienced a symptomatic improvement. A patient may be pleased with a poor result if he was in a very poor condition before treatment and if he does not know how good the result could be. If the criterium of considerable improvement were applied to our series, $94 \%$ of the patients would have been treated successfully. Before treatment $90 \%$ of the patients complained of regurgitation and weight loss; three to 13 years after treatment these symptoms were observed in no more than $6 \%$ of the patients. In this study however, we tried to arrive at an objective evaluation of the patients' symptoms by interviewing them with the aid of an elaborate and carefully prepared questionnaire and by setting out well defined criteria of classification which were rigorously applied by a presumably unbiased occasional collaborator. Using these criteria $77 \%$ of the 133 patients were found to be completely or almost completely free of symptoms at the time of the follow-up study. To arrive at this result seven patients had to undergo more than one series of dilatations.

Further analysis of our data indicates that the best results were obtained in patients who have had symptoms for a period of about five to 20 years and have a moderately dilated gullet with a diameter of 50-80 mm. If the symptoms were present for more than 20 years and if the calibre of the oesophagus exceeded $80 \mathrm{~mm}$, the results were less 
favourable. On the other hand, patients with a short history and only slight oesophageal dilatation also did less well. As the calibre of the oesophagus correlates well with the duration of symptoms, it seems probable that the oesophageal diameter is an important factor in determining the result of pneumatic dilatations.

The manometric studies in untreated patients confirm the previous observations that the resting pressures in the lower oesophageal sphincter of patients with achalasia are within the normal range (Creamer, Olsen, and Code, 1957; Vantrappen, 1961). These studies further indicate that excellent or good results may be expected if the high pressure zone in the lower oesophagus is completely or almost completely abolished at the completion of treatment. If the dilatations did not result in an abolition of this high pressure zone, the patient is likely to have an unsatisfactory result. From this it may be concluded that the aim of treatment of achalasia by pneumatic dilatations should be the abolition of the high pressure zone in the lower oesophagus. It is not always possible, however, to achieve this ideal result. Some patients have been dilated up to a diameter of $5 \mathrm{~cm}$ without complete abolition of the high pressure zone. In others the dilatations had to be stopped suddenly because of complications or fear of complications. Nevertheless, manometric studies seem to be a useful guide for the treatment of achalasia by pneumatic dilatation.

The comparative evaluation of the two major methods of treatment of achalasia, forceful dilatations and the Heller operation, is difficult. Criteria for the classification of the results into 'satisfactory' and 'unsatisfactory' are different from one author to the other and are frequently ill defined. In other reports the follow-up studies are inadequate, due to the insufficient number of patients traced for the follow-up analysis and to the lack of personal interview or objective control examinations. The general impression from a review of the literature is that the results of both methods of treatment are not significantly different. Most reports on the treatment of achalasia by forceful dilatations or the Heller operation claim satisfactory results in $75 \%$ to $85 \%$ of the patients (Nanson, 1966). If the symptoms and signs of the treated patients are analysed in detail the favourable results may be as low as $53 \%$ (Browse and Carter, 1961), whereas cure rates of $95 \%$ are claimed in a series that does not present the long-term results in detail (Schindler, 1956). Gastro-oesophageal reflux and peptic oesophagitis seem to be more of a problem after Heller's operation than after forceful dilatations. Troublesome heart- burn or stenosing oesophagitis is not or rarely observed in patients treated by forceful dilatations (Kurlander, Raskin, Kirsner, and Palmer, 1963). Bennett, Barzaga, Hendrix, and Siegal (1968) considered that gastrooesophageal reflux was the cause of a poor result in two of their 51 patients treated with the Hurst-Tucker pneumatic dilator. The incidence of reflux may amount to $52 \%$ if the patients treated with Heller's operation (Hawthorne, Frobese, and Nemir, 1956). Even if the myotomy is not extended across the oesophagogastric junction into the wall of the cardia in order to prevent reflux, peptic oesophagitis occurred in $4.4 \%$ of the patients (Ellis, Kiser, Schlegel, Earlam, McVey, and Olsen, 1967). It may be that the absence or very low incidence of reflux after forceful dilatation is due to the fact that it is almost impossible to disrupt the oblique fibres of the stomach with a dilator.

\section{References}

Affolter, H., and Voegeli, R. (1969). Erfahrungen mit der pneumatischen Kardia-dilatation bei der Achalasie. Schweiz. med. Wschr., 99, 547-549.

Bennett, J. R., Barzaga, E., Hendrix, T. R., and Siegel, C. I. (1968), Treatment of achalasia by pneumatic dilatation of the cardia. Gut, 9, 727.

Browse, N. L., and Carter, S. J. (1961). The late results of Heller's operation in the treatment of achalasia. Brit. J. Surg., 49, 59-63.

Creamer, B., Olsen, A. M., and Code, C. F. (1957). The esophageal sphincters in achalasia of the cardia (cardiospasm). Gastroenterology, 33, 293-301.

Ellis, F. H., Jr., Kiser, J. C., Schlegel, J. F., Earlam, R. J., McVey, J. L., and Olsen, A. M. (1967). Esophagomyotomy of esophageal achalasia: experimental, clinical, and manometric aspects. Ann. Surg., 166, 640-656.

Ferguson, T. B., and Burford, T. H. (1960). An Evaluation of the Modified Heller Operation in the Treatment of Achalasia of the Esophagus. Ann. Surg., 152, 1-9.

Hawthorne, H. R., Frobese, A. S., and Nemir, P., Jr. (1956). The surgical management of achalasia of the esophagus. Ann. Surg., 144, 653-669.

Kurlander, D. J., Raskin, H. F., Kirsner, J. B., and Palmer, W. L. (1963). Therapeutic value of the pneumatic dilator in achalasia of the esophagus. Gastroenterology, 45, 604-613.

Malm, A. (1956). A 10-year Report of Operated Achalasia of the Esophagus. Gastroenterologia (Basel), 86, 208-210.

Nanson, E. M. (1966). Treatment of achalasia of the cardia. Gastroenterology, 51, 236-241.

Olsen, A. M., Schlegel, J. F., Creamer, B., and Ellis, F. H., Jr. (1957), Esophageal motility in achalasia (cardiospasm) after treatment. J. thorac. Surg., 34, 615-623.

Olsen, A. M. Harrington, S. W. Moersch, H. J., and Andersen, H. A. (1959). The treatment of cardiospasm: analysis of a twelve-year experience. J. thorac. cardiovasc. Surg., 22, 164-187.

Schindler, R. (1956). Observations on cardiospasm and its treatment by brusque dilatátion. Ann. intern. Med., 45, 207-215.

Van Goidsenhoven, G. E., Vantrappen, G., Verbeke, S., and Vandenbroucke, J. (1963). Treatment of achalasia of the cardia with pneumatic dilations. Gastroenterology, 45, 326-334.

Vantrappen, G., Van Goidsenhoven, G., and Vandenbroucke, J. (1961). De behandeling van de achalasia van de cardia met pneumatische dilataties. Resultaten bij een reeks van 57 patiënten. T. Gastro-ent., 4, 600-615.

Vantrappen, G. (1961). Slokdarmmotiliteit. Arscia Uitgaven, Brussels.

Vantrappen, G., Van Goidsenhoven, G. E., Verbeke, S., Van Den Berghe, G., and Vandenbroucke, J. (1963). Manometric studies in achalasia of the cardia, before and after pneumatic dilations. Gastroenterology, 45, 317-325. 